\title{
材料化学专业课程体系 “三点一线”建设模式与实践
}

胡道道*, 刘宗怀, 陈新兵, 雷志斌

陕西师范大学材料科学与工程学院, 西安 710119

摘要: 交叉学科专业的课程体系建设是一个涉及多方面的系统性工程, 是一个有组织的、富有挑战性的创造性过程。针 对多学科交叉专业建设所面临的难题, 本文以陕西师范大学材料化学专业为例, 介绍了基于 “三点一线” 模式的多学科 交叉专业课程体系建设探索与实践, 旨在为多学科交叉专业建设提供借鉴。

关键词: 交叉学科; 新工科; 课程体系; 专业建设; 人才培养

中图分类号: G64; O6

\section{Construction Mode and Practice of "Three Points on One Line " in Curriculum System of Material Chemistry}

Daodao Hu *, Zhonghuai Liu, Xinbing Chen, Zhibin Lei

School of Materials Science and Engineering, Shaanxi Normal University, Xi'an 710119, P. R. China.

\begin{abstract}
The construction of interdisciplinary curriculum system is a systematic project involving many aspects, which is an organized and challenging creative process. In view of the problems faced by multidisciplinary and interdisciplinary specialty construction, taking the material chemistry major of Shaanxi Normal University as an example, this paper introduces the exploration and practice in the construction of curriculum system with multidisciplinary cross-specialty based on the "Three Points on One Line" model, for providing reference in construction of emerging engineering specialty with the features of multi-disciplinary cross.
\end{abstract}

Key Words: Interdisciplinarity; Emerging engineering education; Curriculum system; Major construction; Talent cultivation

\section{1 引言}

学科的产生和学科交叉均是人类对客观世界不断深化认识的必然结果。正如恩格斯在自然辩证 法中所论述的那样, “把自然界分解为各个部门, 把自然界的各种过程和事物分成一定的门类, 对 有机体的内部按其多种多样的解剖形态进行研究, 这是最近四百多年来在认识自然界方面获得巨大 进步的基本条件” [1]。在 16 至 18 世纪期间, 自然科学形成了一门门独立的、系统的、呈现树状结 构的学科体系, 并建立起了相应的学科范式与研究目标, 开始了人类知识体系在学科意义上的分化 过程, 而学科的形成与分化成为认知深化的重要标志。20 世纪 30 年代, 人们逐渐意识到学科分化 在统一化认知客观世界时所存在的固有弊端, 学科发展开始进入到交叉融合阶段。正如量子论创始 人马克斯. 普朗克指出的那样, “科学是内在的整体, 它被分解为单独的整体不是取决于事物的本身, 而是取决于人类认识能力的局限性。实际上存在着由物理学到化学、通过生物学和人类学到社会科

收稿: 2020-08-17; 录用: 2020-08-18; 网络发表: 2020-08-21

“通讯作者, Email: daodaohul@snnu.edu.cn

基金资助: 教育部首批新工科研究与实践项目 


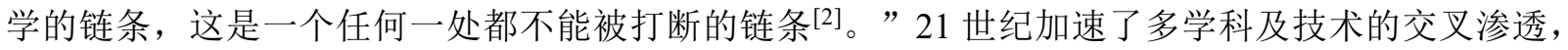
催生了新兴产业, 也推进了高等院校以学科交叉融合为特征的新工科专业建设。以人才培养需求为 依据, 构建多学科交叉融合的课程体系就成为新工科专业建设中不可回避的首要任务。尽管多学科 交叉融合的专业课程体系建设仅是专业建设的一部分, 但在现实实践中, 能够付诸于实践的多学科 交叉专业课程体系却是一个系统性工程，而且富有挑战性 ${ }^{[3]}$ 。

本文以解决新工科多学科交叉专业课程体系建设为主线, 以新工科赖以产生的多学科专业之间 根本性的交叉融合为追求, 在新工科多学科专业课程体系建设的各个主要环节中, 探讨如何有效地 进行多学科深度融合, 并以我校材料科学与工程学院在多学科交叉专业课程体系建设为例介绍, 以 期为相关新专业课程体系建设提供一定的参考和借鉴。

\section{2 交叉学科专业课程体系建设面临的困境}

专业课程体系是实现人才培养目标的具体实施方案, 其建设与学院的交叉学科基础、交叉学科 专业定位及交叉学科体制机制保证有着极为密切的关系。不破解交叉学科建设、多学科专业建设的 难题, 就难以保证多学科交叉专业课程体系的科学性构建与匹配性实施。交叉学科专业建设是一个 涉及多方面的系统性工程, 是一个有组织的创造性过程。这一过程不仅涉及专业建设策略, 更涉及 组织者及参与者对交叉学科专业建设客观需求的认知水平与主观意愿。只有准确认识交叉学科专 业建设面临问题的根源所在, 并采取有效的应对措施, 才能在交叉学科专业建设上取得真正的突 破 ${ }^{[4-6]}$ 。我国高校交叉学科专业建设所面临的有以下有关问题。

1) 缺乏应有的目标追求: 学科交叉应以共同的新视角实现传统学科在交叉学科内涵需求下的契 合性合作, 而非学科利益的纷争。学科交叉已有共识, 但实施往往困难重重。从以往的交叉学科专 业实践不难发现, 当学科交叉与个人及团体利益发生冲突时, 其价值倾向往往已偏离学科交叉的内 涵需求。缺乏对多学科交叉应有的目标追求, 不可能提出有预见性和前瞻性的交叉学科专业建设理 念, 不仅会导致已有多学科交叉专业持续发展受到极大限制, 而且会失去新交叉学科的拓展机会。 交叉学科专业建设理念存在分歧, 必然波及交叉专业课程体系建设。

2) 缺失体制机制保证: 目前我国高校交叉学科专业建设存在两种模式, 一是依附于某个优势学 科学院, 但优先强化传统优势专业往往是学院的普遍策略, 这导致交叉学科专业建设边缘化; 二是 依附于多个二级学院联盟, 但由于以学院为单位的业绩评价机制会导致交叉学科专业建设主体处于 实质性缺失状态。上述两种方式均难以保证交叉学科专业建设得到应有的资源配置。就实践而言, 若不能破解上述问题, 不仅难以形成科学合理的多学科交叉课程体系, 而且也难以保证多学科交叉 课程体系的合理实施。

\section{3 围绕 “三点一线” 专业课程体系的建设与实践}

21 世纪初, 我校在原化学系基础上成立了化学与材料科学学院, 作为交叉学科专业的材料化学 于 2002 获批招收本科生。2011 年学校成立材料科学与工程学院, 重新审视了材料化学专业培养方 案。

事实上, 自 1997 年教育部设置材料化学专业已有 20 多年, 但该专业仍普遍存在社会辨识度低、 师生专业信心不足、社会认可度不高等诸多问题, 这也是多学科交叉专业面临的普遍问题。解决这 一问题的关键在于解决专业特色内涵收玫性与多学科开放性间的矛盾, 归根结底是要解决涉及不适 应交叉学科专业建设的理念和落实理念的体制机制问题。为此, 2011 年学院依据交叉学科专业内在 需求, 以多学科专业人才培养为核心, 确定交叉学科专业方向及其逻辑架构, 以方案为依据确立师 资队伍构成与资源配置; 以实现人才培养目标的内涵为依据, 创设教学实施策略; 以专业建设内在 需求为依据, 建立保障专业建设理念落实和优化资源配置的体制机制, 开展了围绕 “三点一线” 专 业课程体系建设的探索与实践。 


\section{1 多学科交叉专业课程体系建设的体制机制}

交叉学科专业多依附于某个优势学科学院或多个优势学科学院联盟,传统的学科建设惯性思维, 使处于附属弱势地位的交叉学科专业建设常被边缘化。只有突破传统学科建设思维惯性的体制机制, 才能在制度层面保证专业建设理念的有效落实。我校新建材料科学与工程学院, 是一个完全以交叉 学科为特色的独立二级学院, 由于没有传统学科的束缚, 学院在交叉学科建设方面具有了更大自主 空间的体制机制优势。2011 年建院之初, 学院确立了以光电功能材料为特色的学科建设思想, 依照 学科建设与发展内在需求, 构建与之匹配的师资队伍和硬件平台。将教师科研与学科发展相统一, 学科建设与专业建设相统一, 实现交叉学科建设理念的落实和资源的优化配置, 构建了涵盖化学、 物理、材料等多学科背景的师资队伍, 保证了课程体系建设与实施的多学科参与性和师资需求; 相 应硬件资源及科研平台, 极大丰富了多学科交叉实验教学及科研实践资源, 营造了学科交叉融合氛 围, 有效保证了材料化学专业课程体系合理化建设。

\section{2 材料化学专业 “三点一线” 课程体系的构建}

“三点一线”专业课程体系建设, 即以专业落脚点确立专业方向, 以专业着力点定位主体学科, 以专业关切点汇聚交叉学科, 以课程逻辑层次为主线关联交叉学科, 构建特色交叉学科专业培养方 案。

材料化学尽管有着明确的专业界定, 但材料的多样性不仅为材料化学专业建设提供了更大的选 择空间, 同时也给建设富有特色的材料化学专业课程体系带来一定挑战。如何从化学与材料学科知 识体系中凝练具有特征应用需求属性的材料化学专业方向? 如何将所涉及的学科知识高契合性关联 成特色明显的课程体系? 如何使凝练的专业方向既具现实性又具一定前瞻性? 围绕以上问题, 结合 材料化学专业内涵与学科优势, 我们以光电功能为落脚点确定专业方向, 以材料设计合成为着力点 定位化学主体学科, 以光电功能为关切点, 沿 “光电功能材料设计合成-结构表征-性能测试-功能应 用” 主线将化学、物理及材料等学科的相应课程关联起来, 构建以光电功能材料为特色的材料化学 专业课程体系(图 1)。

\begin{tabular}{|c|c|c|}
\hline 结构决定性质 & 性质决定功能 & 功能决定应用 \\
\hline $\begin{array}{l}\text { 宏观: 分子设计合成 } \\
\text { 微观: 组成与结构 }\end{array}$ & $\begin{array}{l}\text { 宏观: 光电性质 } \\
\text { 微观: 功能解析 }\end{array}$ & $\begin{array}{l}\text { 宏观: 组装及性能 } \\
\text { 微观: 性能解析 }\end{array}$ \\
\hline $\begin{array}{l}\text { 专业着力点 } \\
\text { 化学主体学科 }\end{array}$ & $\begin{array}{l}\text { 专业关切点 } \\
\text { 光电性能 }\end{array}$ & $\begin{array}{l}\text { 专业落脚点 } \\
\text { 光电材料 }\end{array}$ \\
\hline
\end{tabular}

图 1 以光电材料为特色的 “三点一线” 材料化学专业课程体系

该课程体系涵盖化学一级学科中的全部五个二级学科, 共 44 个学分, 占总学分的 $27.8 \%$, 旨在 为化学发挥其专业着力点作用奠定坚实基础。开设与光电性能相关的材料基础理论、表征技术及光 电功能材料应用等核心课程以及光电功能相关方向性选修课程总计 29.5 学分, 占总学分的 $24 \%$, 旨 在形成以结构与性能密切关联的光电材料课程群; 开设微观结构与性能测试、光电功能材料制备与 表征的实验课程、材料化学专业课程实践等技能课程, 总学分 11.5 , 占总学分的 $7.2 \%$, 旨在形成从 材料制备、性能表征到实际应用的全程性课程群。技能课程群集中体现了以光电功能为关切点, 将 从分子水平认知材料性能、设计合成材料的化学学科课程与解析光电性能的物理学及材料学相结合。

化学作为从原子及分子层面研究物质结构、组成、性质及变化规律的学科, 具有基础科学属性, 处于自然科学中承上启下的中心学科地位。因此, 以化学学科主干课程为基础, 不仅具有在材料化 
学专业中发挥着力点作用的天然属性, 而且为学生长远发展提供了坚实的学科基础。围绕光电功能 构建的专业核心课程, 具有系统性、方向性和综合性, 能够发挥将化学、物理及材料学科密切联系 的作用, 凸显了交叉学科专业的特色。选修课程群开设了诸多光电材料发展前沿相关课程, 为学生 的职业和个性发展提供宽阔平台。技能课程群涵盖了材料合成与性能测试的专业技能训练, 设计合 成、性能测试及功能化应用于一体, 以交叉学科问题和复杂性问题为研究对象(见表 1)。

表 1 以光电功能材料为特色的材料化学专业课程体系

\begin{tabular}{llll}
\hline \multicolumn{1}{c}{ 基础课程 } & \multicolumn{1}{c}{ 核心课程 } & \multicolumn{1}{c}{ 选修课程 } & \multicolumn{1}{c}{ 技能课程 } \\
\hline 无机化学/实验 & 半导体物理与器件 & 薄膜材料与制备技术 & 新能源材料与器件综合实训 \\
基础有机化学/实验 & 储能技术 & 燃料电池材料与器件 & 新能源材料制备与器件组装 \\
物理化学/实验 & 光电子技术 & 半导体光电子学 & 微结构与物理性能实验 \\
高分子化学与物理/实验 & 材料表征技术 & 光伏材料与器件 & 新能源器件设计与制造工艺 \\
固体物理学 & & 纳米材料学 & 企业管理 \\
电工电子学基础 & & 热电材料与器件 & \\
电化学基础原理 & & 光电子技术 & \\
材料物理性能学 & & 材料表征技术 & \\
材料科学基础 & & 光电检测技术 & \\
材料科学与工程专业导引 & & 胶体化学与界面 & \\
& & 材料力学性能 & \\
& & &
\end{tabular}

\section{3 专业课程资源建设}

师资是学科专业课程体系的建设者和践行者, 其学科背景与多学科交叉专业教学需求的匹配性 决定着课程体系建设的合理性和实施效果。我们以光电功能材料为特色构建了涵盖化学、物理、材 料等多学科背景的师资队伍。其中, 具有化学学科背景的教师 17 人, 具有材料学科背景的 14 人, 具有物理学背景的 7 人, 且所有教师均具有光电功能材料研究经历, 与交叉学科课程体系教学需求 高度匹配。

实现多学科知识与技术高度融合是交叉学科实验/实践课程体系的重点和难点。为此, 围绕光电 功能材料, 我们构建了以 “材料设计合成-结构表征-性能测试-功能应用” 为主要特征的多层次实 验课程体系(表 2), 与之匹配, 先后建成微结构与物理性能测试实验室、无机光电材料制备与表征实 验室、高分子光电材料制备与表征实验室、光电功能材料综合实验室。

这些实验紧紧围绕光电功能材料相关理论与技术, 涉及材料组成与结构、微观形貌、光、电、 磁、热等物理性能测试仪器的原理与使用方法等基础实验; 无机及高分子光电材料制备与表征专业 实验, 涉及高温固相反应法、水热合成法、溶胶凝胶法、无机薄膜制备方法及光刻蚀技术、悬浮聚 合法、乳液聚合法、溶胶凝胶法、偶联聚合法、胶束模板法等诸多材料合成方法, 及扫描电子显微 镜、透射电子显微镜、 $X$ 射线衍射仪、红外光谱仪、热分析仪、荧光光谱仪、紫外可见光谱仪、介 电阻抗仪、比表面及孔径分析仪、光刻机等应用。综合实验实现从光电功能材料合成与表征到器件 化应用的全过程。

表 2 所构建的实验课程体系, 聚焦光电功能, 发挥化学在材料设计合成方面的优势, 并以一体 化思维实验将化学、物理及材料学科沿 “光电功能材料设计合成-结构表征-性能测试-功能应用” 主线关联起来, 形成了理论与实践相结合的实验课程体系, 充分体现了 “三点一线” 多学科交叉专 业课程体系的特点。特别值得说明的是, 我们还专门开设了为期 12 周的材料化学专业实践, 学生分 别进入教师科研实验室, 通过沉浸式参与科研实践, 见证科研课题提出、方案设计、可行性论证、 方案实施、结果分析、论文撰写等全过程, 为学生从验证性实验到创新性实验的过渡提供了桥梁。 
表 2 以光电功能材料为特色的材料化学专业实验课程体系

\begin{tabular}{|c|c|c|c|}
\hline $\begin{array}{c}\text { 微结构与物理性能 } \\
\text { 测试实验 }\end{array}$ & $\begin{array}{c}\text { 无机光电材料制备 } \\
\text { 与表征实验 }\end{array}$ & $\begin{array}{c}\text { 高分子光电材料制备 } \\
\text { 与表征实验 }\end{array}$ & $\begin{array}{l}\text { 光电功能材料 } \\
\text { 综合实验 }\end{array}$ \\
\hline 56 学时 & 70 学时 & 56 学时 & 56 学时 \\
\hline 霍尔效应 & 压电陶瓷粉体制备与表征 & 超吸水性聚合物微球反相乳液聚合 & 超级电容器组装及其应用展示 \\
\hline 铁电材料性能测试 & 压电陶瓷制备及性能测试 & 液晶高分子薄膜制备与性能表征 & $\begin{array}{l}\text { 染料敏化太阳能电池组装及其 } \\
\text { 应用展示 }\end{array}$ \\
\hline$X$ 射线衍射分析 & 共沉淀法制备苂光粉及其发光性能 & $\begin{array}{l}\text { 表面活性剂胶束模板合成有序介孔 } \\
\text { 材料 }\end{array}$ & $\begin{array}{l}\text { 压电陶瓷贾卡梳的制备及压电 } \\
\text { 效应演示 }\end{array}$ \\
\hline 热重分析 & 氧化锌薄膜制备及其光致苂光测量 & 导电高分子聚苯胺合成与性能测试 & 燃料电池组装及其应用展示 \\
\hline 太阳能电池特性测试 & 超顺磁性纳米晶合成及其性能表征 & 基于菲酰亚胺的发光凝胶 & 氮化钨制备及其光解水应用 \\
\hline 多孔材料比表面积测试 & 硅/玻璃基质上金膜光刻蚀图案化 & 共轭微孔聚合物合成及其发光性能 & \\
\hline 材料应力-应变曲线测定 & 锂离子电池电极材料制备及表征 & 聚烷氧基对苯乙炔制备及发光 & \\
\hline 红外光谱分析 & 纳米氧化钛制备及光催化 & & \\
\hline 液晶电光效应特性研究 & & & \\
\hline
\end{tabular}

\section{4 结语}

交叉学科专业建设是一项极具挑战性的系统性工作。“三点一线” 交叉学科课程体系建设模式 的提出与实施, 得益于新建材料科学与工程学院无学科偏见的体制机制、多学科交叉背景的师资队 伍和学科平台。多学科背景师资队伍参与保证了课程体系构建的合理性, 保证了与课程体系匹配的 师资队伍建设及硬件资源优化配置。近十多年的实践表明, 该建设模式在提升专业水平及人才培养 质量方面的优势日益凸显，为培养高素质交叉复合型创新人才提供了借鉴。

\section{参 考 文 献}

[1] 恩格斯. 马克思恩格斯选集 第 3 卷. 北京: 人民出版, 1995: 359 .

[2] 卢启文. 北京大学学报(哲学社会科学版), 1988, No. 3, 67 .

[3] 王淑芳, 宋存江, 丁丹, 赵强, 张钩, 杨超. 高校生物学教学研究(电子版), 2016, 6 (2), 7.

[4] 罗勤, 梁传杰. 高等工程教育研究, 2016, No. 4, 189.

[5] 林健. 高等工程教育研究, 2018, No. 1, 32.

[6] 李培根. 中国高等教育, 2007, No. 8,4 . 